\title{
Glomerular filtration rate evaluation and its comparison with international standard values in a large population- based study
}

\author{
Seyed Javad Hoseini ${ }^{(\mathbb{D}}$, Ehsan Mosa Farkhani², Hamid Reza Bahrami ${ }^{3}$, Reza Eftekhari Gol ${ }^{4}$, Saied \\ Bokaie $^{5}$, Behnaz Beygi ${ }^{*} \mathbb{D}$ \\ ${ }^{1}$ Department of Medical Biotechnology, School of Medicine, Mashhad University of Medical Sciences, Mashhad, Iran \\ ${ }^{2}$ Khorasan Razavi Province Health Center, Mashhad University of Medical Sciences, Mashhad, Iran \\ ${ }^{3}$ Complementary and Chinese Medicine, Persian and Complementary Medicine Faculty, Mashhad University of Medical Sciences, \\ Mashhad, Iran \\ ${ }^{4}$ Department of Health Network Development and Health Promotion, Mashhad University of Medical Sciences, Mashhad, Iran \\ ${ }^{5}$ Epidemiology and Zoonosis Division, Department of Food Hygiene, Faculty of Veterinary Medicine, University of Tehran, Tehran, Iran \\ and Uro-Oncology Research Center, Tehran University of Medical Sciences, Tehran, Iran \\ ${ }^{6}$ Environmental Health Engineering, Khorasan Razavi Province Health Center, Mashhad University of Medical Sciences, Mashhad, Iran
}

\begin{tabular}{l} 
A R T I C L E I N F O \\
\hline Article Type: \\
Original \\
\hline
\end{tabular}

\section{Article History:}

Received: 3 February 2019

Accepted: 15 April 2019

Published online: 18 May 2019

\section{Keywords:}

Glomerular filtration rate

Cockcroft-Gault formula

Hypertension

Hyperlipidemia

Chronic kidney disease

\begin{abstract}
A B S T R A C T
Introduction: The definition of the distance between the mean and reference value for the glomerular filtration rate (GFR) has been the topic of few performed studies, which resulting in an inconsistent mean difference.

Objectives: This study was aimed to determine the normal GFR reference range for Iranian population and its comparison with global average.

Patients and Methods: Data of the study population was extracted from Sina Health Record System (SinaEHR ${ }^{\circledR}$ ). Based on the blood creatinine level, the GFR was calculated by CockcroftGault formula. Using statistical analyses and independent t-test, GFR distribution was evaluated by the STATA software.

Results: In this study the mean GFR in the Iranian population was estimated as $111.52 \mathrm{~mL} /$ $\min / 1.73 \mathrm{~m}^{2}$ (CI: 111.30-111.73). When comparing results of this study with an international meta-analysis, it was revealed that before 45 years, the mean GFR in the Iranian population is higher than the standard mean value in the meta-analysis, whereas it is lower than the mentioned value after the age of 45 years. Moreover, the results demonstrated a significant difference in the mean GFR between men and women over 40 years of age $(P<0.001)$. In those cases suffering from hypertension, hyperlipidemia or diabetes, the mean GFR was lower than healthy individuals $(P<0.05)$, however, this difference was not significant for diabetic patients $(P=0.580)$.

Conclusion: The difference between our large population-based study and meta-analysis shows the need for more precise studies to better determine standard range of GFR in the Iranian population.
\end{abstract}

Implication for health policy/practice/research/medical education:

In a study on 105725 cases with an age range of 20-100 years, GFR in Iranian population was estimated as $111.52 \mathrm{~mL} / \mathrm{min} / 1.73 \mathrm{~m}^{2}$. Please cite this paper as: Hoseini SJ, Mosa Farkhani E, Bahrami HR, Eftekhari Gol R, Bokaie S, Beygi B. Glomerular filtration rate evaluation and its comparison with international standard values in a large population-based study. J Nephropharmacol. 2019;8(2):e23. DOI: 10.15171/npj.2019.23.

\section{Introduction}

Chronic kidney disease (CKD) is referred to a group of pathologic conditions that are associated with abnormal kidney function and progressive loss of glomerular filtration rate (GFR) (1). Today, it is an issue of public health concern worldwide (2). In 2012 the World Health Organization attributed around 864226 or $1.5 \%$ of all global mortalities to this disease (3). The risk of developing cardiovascular disease and mortality in CKD patients is higher than normal individuals and greatly affects the health system (4). The current CKD guidelines are focused on standardizing the severity of the disease and designing strategies for its treatment $(5,6)$.

GFR is regarded as the most reliable indicator for 
kidney function. The predicted prevalence of $\mathrm{CKD}$ in any population is related to the formula which is used for calculating the GFR. Therefore, the proper estimation of GFR has a prominent role in the diagnosis of CKD, which is necessary for the nephrology setting (7). The most precise method for measuring the GFR is the evaluation of filtration of inulin and iothalamate indices. However, due to the difficulties, its high costs and the effect of radiation on the body, they have limited use in clinical practice. The other index for estimating kidney function is the level of serum urea nitrogen and creatinine concentration. Today the most common method for GFR calculation is measurement of the 24-hour urine and the serum and urine creatinine concentration (1). The mean GFR for the healthy population (children, adolescents and adults) up to the age of 40 years is $107.3 \mathrm{~mL} / \mathrm{min} / 1.73 \mathrm{~m}^{2}$, while the reduction in GFR begins at the age of 40 (8).

According to international guidelines on $\mathrm{CKD}$, reduced kidney function occurs over three months. When the GFR reduces to less than $15 \mathrm{~mL} / \mathrm{min} / 1.73 \mathrm{~m}^{2}$, the patient has entered the terminal phase of the disease and the kidney function at that time would not be able to sustain a longterm life (9).

\section{Objectives}

The present study was aimed to determine the GFR in terms of gender in a large population-based setting of adults in Khorasan-Razavi province. Given the large volume of information, the results of this study can be generalized to the Iranian population and the normal reference range of GFR can be determined among the Iranian people.

\section{Patients and Methods \\ Data collection}

In this descriptive cross-sectional study, the data of the studied population was extracted from the data bank of Sina Electronic Health Record system (SinaEHR ${ }^{\oplus}$ ) supervised by Mashhad University of Medical Sciences. The information of individuals over the age of 20 years was collected. The data recorded in this system include the health records of each individual, reports of physicians and health care providers, prescribed drugs, laboratory results, procedures, diagnoses, and other details of each patient's case. This system which covers the data of over five million individuals in Khorasan-Razavi province. This system is an integrated health system that is managed by the cooperation and coordination of all stakeholders including managers, physicians, midwives, health care providers, etc. In this system the demographic and anthropometric information along with the health information of the covered population is recorded electronically.

To calculate the GFR, the Cockcroft -Gault formula in the SinaEHR software database was used (10). For women;
$(140$ - AGE $) \times$ weight $) /(84.7 \times \mathrm{CR})$ and for men; $(140$ AGE) $\times$ weight $) /(72 \times \mathrm{CR})$.

In this formula, weight and serum creatinine was measured in a laboratory by the enzymatic method for the covered population and recorded in the SinaEHR software. The data were extracted from the electronic records database in the form of an excel file.

In this study patients with ICD10 codes including E11 and E10 were regarded as diabetic cases and those with I10, I11 and I15 codes were considered as hypertension while individuals with the diagnostic code of E78 were registered as hyperlipidemia cases.

\section{Ethical approval}

The research followed the tenets of the Declaration of Helsinki and its later amendments. The design and objectives of the investigation were explained to all participants and written informed consent was obtained from the participants. This study was conducted after obtaining the research approval from the ethics committee of Mashhad University of Medical Sciences (IR.MUMS. REC.1396.361).

\section{Statistical analysis}

The statistical analysis of GFR distribution was done with the STATA software (version 14). The box-plot graph was used to show the median, mean and the 25th, 75th, 99th and 1 percentile based on age and gender. The difference in mean GFR in terms of gender was evaluated using independent sample $t$ test. The GraphPad software was applied for drawing the graphs.

Results

A totlal of 105725 cases with an age range of 20-100 years were studied in this research. Table 1 and Figure 1 present the mean and standard deviation of GFR based on the different age groups. With an increase in age, the mean GFR decreased in both genders, while the decrease

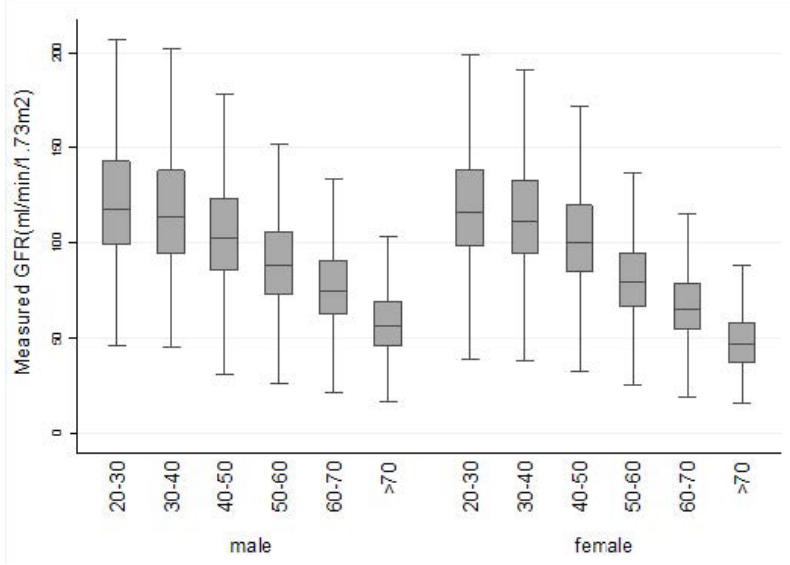

Figure 1. Box plot graph of GFR values in different age groups in terms of sex. 
Table 1. Comparison of mean and standard deviation of GFR in different age groups based on sex

\begin{tabular}{|c|c|c|c|c|c|c|c|}
\hline \multirow{2}{*}{ Age (y) } & \multicolumn{3}{|c|}{ Male } & \multicolumn{3}{|c|}{ Female } & \multirow{2}{*}{$P$ Value } \\
\hline & Mean & SD & $95 \% \mathrm{Cl}$ & Mean & SD & $95 \% \mathrm{Cl}$ & \\
\hline $20-30$ & 122.74 & 2.08 & $(118.66-126.83)$ & 121.09 & 0.16 & (120.78-121.39) & 0.111 \\
\hline $30-40$ & 118.24 & 1.34 & (115.61-120.87) & 116.16 & 0.16 & $(115.85-116.48)$ & 0.335 \\
\hline $40-50$ & 108.11 & 1.28 & $(105.60-110.62)$ & 104.76 & 0.36 & $(104.05-105.47)$ & 0.000 \\
\hline $50-60$ & 92.34 & 0.98 & $(90.41-94.27)$ & 82.60 & 0.44 & $(81.73-83.46)$ & 0.000 \\
\hline $60-70$ & 79.04 & 0.60 & (77.86-80.21) & 68.45 & 0.33 & (67.79-69.09) & 0.000 \\
\hline$>70$ & 59.52 & 0.49 & (58.55-60.49) & 49.07 & 0.35 & (48.39-49.75) & 0.000 \\
\hline
\end{tabular}

was greater in women compared to men. Although no significant difference was seen in the mean GFR between the men and women under 40 years of age $(P>0.05)$, yet this difference was greater in men and women over the age of 40 years. Moreover, the decrease in mean GFR had a deeper slope among women in comparison to men $(P<0.001)$. Accordingly, the highest rate in men and women in the age range of 20-30 years was $122.74 \pm 2.08$ $\mathrm{ml} / \mathrm{min} / 1.73 \mathrm{~m}^{2}$ (CI: 118.66-126.83) and $121.09 \pm 0.16 \mathrm{ml} /$ $\mathrm{min} / 1.73 \mathrm{~m}^{2}(\mathrm{CI}=120.78-121.39)$, respectively. This rate reduced to $59.52 \pm 0.49 \mathrm{~mL} / \mathrm{min} / 1.73 \mathrm{~m}^{2}(\mathrm{CI}=58.55-60.49)$ and $49.07 \pm 0.35 \mathrm{~mL} / \mathrm{min} / 1.73 \mathrm{~m}^{2}(48.39-49.75)$ among men and women with the age over 70 years respectively. The distribution chart for GFR in terms of age is shown in Figure 2. The results indicate a decline in its rate with aging.

In this study the relationship between GFR and non-communicable diseases such as hypertension, hyperlipidemia and diabetes was studied. The results presented in Table 2 show that the GFR in such cases is less than normal individuals, indicating a statistically significant difference for hypertension and hyperlipidemia

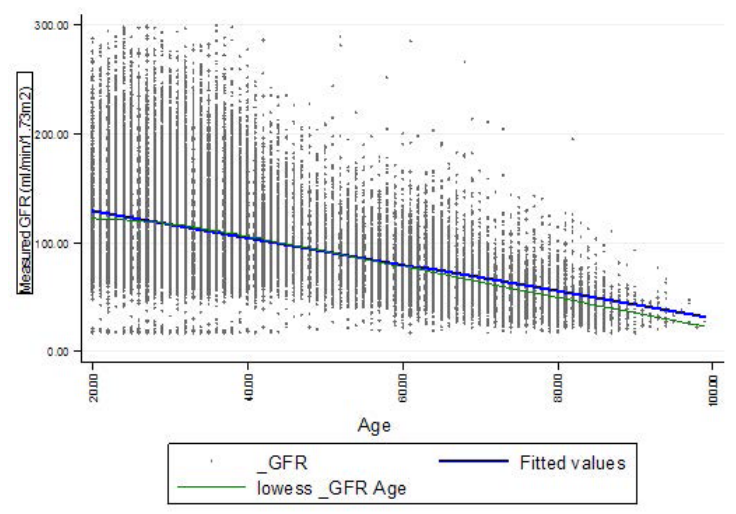

Figure 2. Dispersion of age and GFR of the studied cases.
$(P<0.05)$, but not for diabetes $(P=0.580)$.

To compare our results with international standards, the results of a meta-analysis which its mean, standard deviation and $95 \%$ CI was reported in the study of Pottel et al, was applied. The results of the mentioned metaanalysis are displayed in Table 3. The comparison of the figures in that table with the results achieved in our study is presented in Figure 3. We found before the age of 45 years, the mean GFR in the Iranian population is higher than the mean value in the meta-analysis. However, it is lower than the standard mean value after the age of 45 years. In order to accept or reject the hypothesis that the mean value obtained in our study is different from the mean value reported in the meta-analysis, one-sample $t$ test was used resulting in the acceptance of this hypothesis $(P<0.001)$.

\section{Discussion}

In this study, the GFR was calculated for patients in different age groups and accordingly a new GFR reference value was achieved for the study population based on the international reference. Regarding the large amount of data, this value can be generalized to the entire population of Iran. In this study the GFR was compared in the two groups of under and over 45 years of age. Based on the reference value of $107.3 \mathrm{~mL} / \mathrm{min} / 1.73 \mathrm{~m}^{2}$, a significant difference in the GFR was obtained between the study population and the reference value.

The mean value of $107.3 \mathrm{~mL} / \mathrm{min} / 1.73 \mathrm{~m}^{2}$ was initially calculated by Piepsz et al (12) for 2 to 14 years old children in 2013. It was expanded to teenagers and the youth age group by Pottel et al in 2016 (14). In 2017 it was generalized and used for the middle-aged and elderly population (15). Our study showed that GFR level is above the standard level in 20 to 45 years, whereas in ages of 45 it showed a premature decline in kidney function. Moreover, beyond 45 years, GFR decreases by 1.85 units. In different studies,

Table 2. Comparison of mean and standard deviation of GFR in relation to non-communicable diseases

\begin{tabular}{|c|c|c|c|c|c|c|c|}
\hline \multirow{2}{*}{ Variable } & \multicolumn{3}{|c|}{ Yes } & \multicolumn{3}{|c|}{ No } & \multirow{2}{*}{$P$ Value } \\
\hline & Mean & SD & $95 \% \mathrm{Cl}$ & Mean & SD & $95 \% \mathrm{Cl}$ & \\
\hline Hypertension & 64.19 & 0.28 & $(63.64-64.73)$ & 115.14 & 0.11 & (114.93-115.35) & 0.001 \\
\hline Hyperlipidemia & 65.67 & 0.37 & (64.94-66.41) & 113.29 & 0.11 & (113.07-113.51) & 0.000 \\
\hline Diabetes & 67.99 & 1.60 & $(64.85-71.34)$ & 111.65 & 0.11 & (111.44-111.87) & 0.580 \\
\hline
\end{tabular}


Table 3. Mean and confidence interval obtained from the meta-analysis study for GFR (ml/min/1.73 $\left.\mathrm{m}^{2}\right)$

\begin{tabular}{llll}
\hline Age groups & Number of studies & Mean & Cl (95\%) \\
\hline $20-30$ & 22.24 & 106.7 & $104.6-108.9$ \\
$30-40$ & 22.24 & 104.9 & $102.8-107.0$ \\
$40-50$ & 20.24 & 99.0 & $96.5-101.6$ \\
$50-60$ & 18.24 & 90.7 & $88.1-93.3$ \\
$60-70$ & 14.24 & 84.0 & $79.5-88.5$ \\
$>70$ & 6.24 & 69.4 & $66.1-72.2$ \\
\hline
\end{tabular}

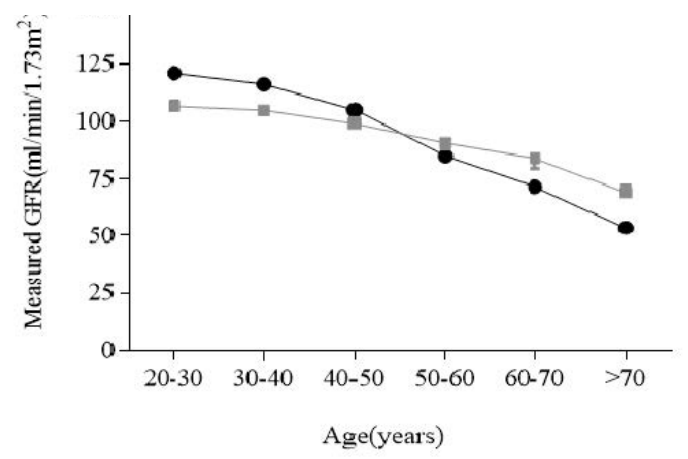

Figure 3. Comparison of the mean and confidence interval obtained in the present study and the standard values reported in the meta-analysis.

the age threshold for a decrease in GFR has been reported as 40 years (16).

In the current study, no significant difference was observed in GFR between the two genders under the age of 40 years; however, among those over 40 years a significant decrease was observed in females in comparison to males. In the meta-analysis by Pottel et al, this significant decrease was reported after 50 years of age (11). Poggio et al observed such a significant difference even in those under 50 years of age. Their study showed that age and gender are the two main factors which affect renal function (17). The reason for this difference may be related to the difference in ethnicity and the large sample size.

The results also indicate a decrease in GFR in cases with hypertension and hyperlipidemia. In the study by Rigalleau et al (18) the mean and standard deviation of GFR in diabetic patients was $65.5 \pm 37.5 \mathrm{~mL} / \mathrm{min} / 1.73 \mathrm{~m}^{2}$. In the study by Lewis et al (19) the mean GFR in hypertensive subjects was reported as $56.9 \mathrm{~mL} / \mathrm{min} / 1.73 \mathrm{~m}^{2}$ which is consistent with the findings of the present study. This may be due to the effect of such diseases on kidney function resulting in a decrease in GFR.

This study had certain limitations such as the lack of comparisons between the three standard GFR calculation formulas, as the results were compared with the results of the meta-analysis which was based only on the CockcroftGault formula. Moreover, the existence of outliers or missing data among the primary extracted data and their elimination from the final analysis can be mentioned. On the other hand, the large sample size, the populationbased setting and comparison with international results can be mentioned as the strong aspects of the study.

\section{Conclusion}

In this study the mean GFR in the Iranian population was estimated as $111.52 \mathrm{~mL} / \mathrm{min} / 1.73 \mathrm{~m}^{2}$ (CI: $111.30-111.73$ ). Comparing these results with that of an international meta-analysis shows that before the age of 45 years, the mean GFR in the Iranian population is higher than the meta-analysis mean value, but the opposite result is achieved after the age of 45 years. The different results observed in this population-based study shows the need for more precise studies to better determine the standard range of GFR in the Iranian people based on all its calculation formulas.

Limitations of the study

Our data requires further investigation by a larger sample size.

\section{Authors' contribution}

$\mathrm{SJH}, \mathrm{HRB}, \mathrm{BB}$ and MF contributed to study design, preparation of manuscript and final revision. HRB and REG participated in data gathering. MF conducted data analysis and interpretation. All authors read and approved the paper.

\section{Conflicts of interest}

The authors declared no competing interests.

Ethical considerations

Ethical issues which include plagiarism, data fabrication, double publication have been completely observed by the authors.

\section{Funding/Support}

The authors would like to thank the research chancellor of Mashhad University of Medical Sciences for funding (\#951066).

\section{References}

1. Rafati Fard M, Taghian F, Pakfetrat M, Daryanoosh F, mohammadi $\mathrm{H}$. The Effect of aerobic training on the Amount of GFR and excreted of Creatinine in Patients with Chronic kidney. J Army Univ Med Sci. 2011;9:264-70.

2. Chang YK, Hsu CC, Chen PC, Chen YS, Hwang SJ, Li TC, et al. Trends of cost and mortality of patients on hemodialysis with end stage renal disease. Nephrology (Carlton). 2015; 20:243-9. doi: 10.1111/nep.12380.

3. Webster AC, Nagler EV, Morton RL, Masson P. Chronic Kidney Disease. Lancet. 2017;389:1238-1252. doi: 10.1016/ S0140-6736(16)32064-5

4. Tsai CW, Ting IW, Yeh HC, Kuo CC. Longitudinal change in estimated GFR among CKD patients: A 10-year follow- 
up study of an integrated kidney disease care program in Taiwan. PLoS One. 2017;12:e0173843. doi: 10.1371/journal. pone. 0173843

5. Inker LA, Astor BC, Fox CH, Isakova T, Lash JP, Peralta CA, et al. KDOQI US commentary on the 2012 KDIGO clinical practice guideline for the evaluation and management of CKD. Am J Kidney Dis. 2014;63:713-35. doi: 10.1053/j. ajkd.2014.01.416.

6. KDIGO CKD Work Group. Clinical practice guideline for the evaluation and management of chronic kidney disease. Kidney Int Suppl. 2013; 3:150-6.

7. Botev R, Mallié JP, Wetzels JF, Couchoud C, Schück O. The clinician and estimation of glomerular filtration rate by creatinine-based formulas: current limitations and quo vadis. Clin J Am Soc Nephrol. 2011; 6:937-50. doi: 10.2215/ CJN.09241010.

8. Pottel H, Delanaye P, Schaeffner E, Dubourg L, Eriksen BO, Melsom T, et al. Estimating glomerular filtration rate for the full age spectrum from serum creatinine and cystatin C. Nephrol Dial Transplant. 2017; 32:497-507. doi: 10.1093/ ndt/gfw425.

9. Levey AS, Inker LA, Coresh J. GFR estimation: from physiology to public health. Am J Kidney Dis. 2014; 63:82034. doi: 10.1053/j.ajkd.2013.12.006.

10. Botev R, Mallié JP, Couchoud C, Schück O, Fauvel JP, Wetzels JF, et al. Estimating glomerular filtration rate: Cockcroft-Gault and Modification of Diet in Renal Disease formulas compared to renal inulin clearance. Clin J Am Soc Nephrol. 2009; 4:899-906. doi: 10.2215/CJN.05371008.

11. Pottel H, Hoste L, Yayo E, Delanaye P. Glomerular Filtration Rate in Healthy Living Potential Kidney Donors: A MetaAnalysis Supporting the Construction of the Full Age Spectrum Equation. Nephron. 2017; 135:105-119. doi: $10.1159 / 000450893$.

12. Piepsz A, Tondeur M, Ham H. Escaping the correction for body surface area when calculating glomerular filtration rate in children. Eur J Nucl Med Mol Imaging. 2008; 35:1669-72. doi: 10.1007/s00259-008-0820-3.

13. Hoste L, Dubourg L, Selistre L, De Souza VC, Ranchin B, Hadj-Aïssa A, Cochat P, Martens F, Pottel H. A new equation to estimate the glomerular filtration rate in children, adolescents and young adults. Nephrol Dial Transplant. 2014; 29:1082-91. doi: 10.1093/ndt/gft277.

14. Pottel H, Hoste L, Dubourg L, Ebert N, Schaeffner E, Eriksen BO, et al. An estimated glomerular filtration rate equation for the full age spectrum. Nephrol Dial Transplant. 2016; 31:798-806. doi: 10.1093/ndt/gfv454.

15. Pottel H, Delanaye P, Schaeffner E, Dubourg L, Eriksen BO, Melsom T, et al. Estimating glomerular filtration rate for the full age spectrum from serum creatinine and cystatin C. Nephrol Dial Transplant. 2017; 32:497-507. doi: 10.1093/ ndt/gfw425.

16. Pottel H, Delanaye P, Weekers L, Selistre L, Goffin K, Gheysens O, et al. Age-dependent reference intervals for estimated and measured glomerular filtration rate. Clin Kidney J. 2017; 10:545-551. doi: 10.1093/ckj/sfx026.

17. Poggio ED, Rule AD, Tanchanco R, Arrigain S, Butler RS, et al. Demographic and clinical characteristics associated with glomerular filtration rates in living kidney donors. Kidney Int. 2009; 75:1079-87. doi: 10.1038/ki.2009.11.

18. Rigalleau V, Lasseur C, Perlemoine C, Barthe N, Raffaitin C, Liu C, Chauveau P, Baillet-Blanco L, Beauvieux MC, Combe $\mathrm{C}$, Gin H. Estimation of glomerular filtration rate in diabetic subjects: Cockcroft formula or modification of Diet in Renal Disease study equation? Diabetes Care. 2005; 28:838-43.

19. Lewis J, Agodoa L, Cheek D, Greene T, Middleton J, O'Connor D, et al. Comparison of cross-sectional renal function measurements in African Americans with hypertensive nephrosclerosis and of primary formulas to estimate glomerular filtration rate. Am J Kidney Dis. 2001;38:744-53

Copyright $\odot 2019$ The Author(s); Published by Published by Society of Diabetic Nephropathy Prevention. This is an open-access article distributed under the terms of the Creative Commons Attribution License (http://creativecommons.org/licenses/by/4.0), which permits unrestricted use, distribution, and reproduction in any medium, provided the original work is properly cited. 